\title{
65
}

\section{Technology and learning: computer mediated communication between deaf children}

\author{
Rosa Maria Bottino \\ Giampaolo Chiappini \\ Consiglio Nazionale delle Ricerche - Istituto per la Matematica \\ Applicata \\ Genova \\ Italy
}

\begin{abstract}
This paper refers to a research study concerning the use of the RETE system which was developed for distance communication between deaf pupils (by means of computers connected via modems). The research is aimed at verifying the role of computers in the development of communication capabilities in written language which deaf children only with difficulty develop. We analyze the educational context of the use of the RETE system in two different, but complementary approaches. The first is analytical and based on different models which describe the characteristics of the educational context. The second approach is systemic and analyzes the cognitive, motivational and social effects of the user's activity. The methodology adopted is of a general character and can also be used to analyze learning situations in which computers are used as learning tools.
\end{abstract}

Main conference themes: learner centred learning

Educational areas: primary education

Study topics:

Secondary keywords: communication, learning systems, special needs 


\section{CONTENT OF THE STUDY}

\section{The project}

The project, supporting distance communication between deaf children in primary school, consists of three different experiments realized in the space of three years.

The first experiment concerned computer mediated dialogue between seven children in different schools: three deaf students in a normal school setting and four deaf students in a 'deaf only' classroom setting. This experiment consisted of weekly, one to one, communication sessions of 30 to 40 minutes during a period of six months [1]. The second experiment concerned a dialogue between a deaf adult (with a good level of schooling) and a deaf pupil. This experiment consisted of weekly communication sessions of 30 to 40 minutes during a period of five months [1]. The third experiment concerned a dialogue between two groups of deaf children living in different towns. This experiment consisted of 6 communication sessions of 90 to 120 minutes each. All computer mediated communication was in the form of written language (Italian).

The experiments were run in computer laboratories equipped with personal computers and modems. All experiments were directly and constantly monitored. The evaluation of students' behaviour was done by analyzing the observation protocols and the record of the communication sessions.

The dialogue between the two groups of deaf children who lived in different towns, was characterized by a process of negotiation, within each group, about content and form of dialogue statements to be send to the other group.

The dialogue between the deaf child and the deaf adult enabled the child to communicate with a person who could adapt to the child's expressive capabilities and who could at the same time select and correct syntactic forms. The deaf adult offered the student a positive role model.

The dialogue between two deaf children of the same age broke their isolation and made comparison with a peer possible.

\section{The software system}

The RETE system was specifically designed and implemented for these experiments. It is implemented in Hypercard 2.1 using the HyperTalk programming language and is running on Apple Macintosh computers. Through this system, running on computers connected via modems or local networks, users have on-line dialogues. The system allows its users to:

- choose a partner to communicate with;

- exchange written messages; 
- reread the whole dialogue with a partner;

- automatically save each dialogue;

- send or receive text files previously prepared;

- send or receive graphical files previously prepared with the graphic editor of the system;

- manage a data base of names and telephone numbers of communication partners.

The user interface of the RETE system, which is entirely mouse driven, is designed to make use of the different system functions easy and straightforward. It automatically takes account of changes caused by the user's actions. A menu of commands offers access to the different functions. This design makes the system easy to use for beginners and young students, and allows for rapid familiarization, as we were able to verify during the experiments.

\section{ANALYSIS OF THE EDUCATIONAL CONTEXT}

\section{The analytical approach}

In this approach the different models on which its design is based, are analyzed.

\section{Relevant theory}

Recent research in linguistics and psycholinguistics shows that oral and written language differ not only because of the different physical means through which these are expressed, but also in the different cognitive and social mechanisms which play a role in their use. This nontraditional way of looking at the relation between oral and written language is of crucial importance in the pedagogical field. In fact, studies on how reading and writing capabilities are developed present the 'transcription mechanism' as a model of written language. This mechanism is based on a set of rules which allow one to represent a sequence of oral sounds in graphic signs. Although this model allows one to identify certain peculiar features in the relationship between oral and written language, it cannot explain what learning reading and writing generally means (see, for example, [2] and [3]). This is confirmed by what usually occurs in school practice where mastering of the transcription rules does not guarantee the actual development of writing capabilities. Also, being able to 'decode' a written text does not guarantee its real understanding. It follows that the development of this transcription capability is not, as a rule, a sufficient condition for the learning of writing. Ferreiro and Teberosky [2] show that this 
pedagogical approach works only with those children who are able to find a relationship between language and writing, and also only when they have reached a linguistic development which enables them to integrate visual with nonvisual information. Students, and deaf children in particular, do not automatically operate on this conceptual level.

\section{The student model}

The development of oral language in deaf children when they begin to read and write (at the age of about 6) is as a rule poor in comparison with that of hearing pupils of the same age. It is widely documented that such delay in development greatly affects the learning performance [4]. The traditional educational approach does not seem to be able to overcome the difficulties deaf children encounter in this respect. In this approach reading and writing activities are often reduced to purely mechanical activities, focused on transcription aspects (i.e. of lip movements) and on decoding and articulating the written code. These activities are often not associated with any real need for giving meaning to these codes. This kind of teaching is far removed from the true communication needs of deaf pupils and their actual linguistic development, and in most case does not offer any effective learning motivation by lack of usefulness. It further hinders the development of fundamental cognitive processes such as anticipation of meaning in reading and speech planning in writing.

\section{The learning model}

An important aspect of an educational setting in which disabled students are involved, is the balance between development of specific capabilities and more general needs. These general needs are not so much concerned with knowledge acquisition, but mainly with communication. In the research we are describing, communication activities are not the means through which reading and writing capabilities are developed, but the goal itself of the educational process.

\section{Characteristics of the communication situation}

The main features of the computer mediated dialogues and of the programmed pedagogical activities are described.

\section{Modes of dialogue}

Computer mediated dialogue, as well as oral dialogue, develops through a chain of reactions, of reciprocal replays and explanations between interlocutors who 
alternatively play the role of sender and receiver. The dialogue is successful when cooperation is established between the two interlocutors. This is only accomplished when the interlocutors share the same objectives which, during the interaction, are implicitly and dynamically defined, but which may also change in the course of time. In dialogue interlocutors are always aware of the subject matter of the conversation and of its development.

\section{The computer mediation}

The communication context accomplished through computer mediation allows development of dialogues through means which are specific for written language and which make these dialogues considerably different from oral dialogues [5]. This does, however, not imply that these dialogues may be compared to written monologue; their peculiarities make them notably different from this form of communication. As opposed to oral dialogues, the computer mediation offers the user a number of extra opportunities:

- using external memory as planning support;

- recalling the text of messages previously sent by the interlocutor;

- reviewing the whole conversation which took place;

- correcting and modifying each message statement before transmitting it to the interlocutor.

\section{Form of the dialogue}

The communication context in question leads to a very different use of written language. Actually the written dialogue carried out through computers has a nonformal character and uses simplifications which are usually not possible in written language. Importance is attached to the substance of the message and to its capacity of expressing a communication meaning. Other parameters such as syntax and style are less emphasized.

We note that, in such a communication context, the cognitive processes involved in learning written language may benefit from an interaction mechanism which is not present when written language is used in monologues. This appears to be particularly useful to deaf children in that it helps realize cognitive processes which they would be unable to carry out on their own nor with the assistance of an adult. We refer, for example, to the cognitive processes involved in anticipating the content of written messages or in planning communication acts.

\section{Balance between development of capacity and communication needs}

Computer mediated dialogue sets pedagogical problems. Which behaviour should be adopted when a pupil commits a gross error, depending on whether 
an adult is the pupil's interlocutor or whether the adult merely helps with the activity. The choice between correcting and not correcting is a choice between favouring knowledge or communication needs. In our experiments we decided to try to address both needs through a temporal scanning allowed by the peculiar features of the communication setting. During the communication activity the adult strictly abstained from intervening, unless so expressly invited by the pupil. The structure of the sentences used and their eventual correction were only considered after the communication activity was over, by working on the print of the complete dialogue.

\section{The systemic approach}

The systemic approach analyzes the motivational, social and cognitive effects of student activities in the educational setting which result from the combined features of context which reciprocally influence each other in the pupil's activity.

\section{Social and motivating effects}

Computer mediated dialogue gives deaf children the opportunity to communicate with different persons thereby extending their communicative experience in ways they can easily control. To be able to understand and be understood are strong motivations for children. The increment in motivation could also be perceived in the eagerness pupils showed in reading and writing activities related to computer mediated dialogues. This also creates the conditions for development of both cognition and selfreliance.

The experiments also give evidence of the potentials offered by the educational context with respect to the social environment. In the different activities pupils always wanted to know each other personally and always took advantage of these new social contacts.

\section{Cognitive effects}

The cognitive effects which resulted from the computer activities, mainly concern development of the following capabilities: anticipation of meaning in reading, planning in writing and development of lexical and syntactic experience in writing.

\section{Development of anticipation in reading}

The communication context in which dialogues are carried out, favours the development of those anticipation processes which are essential to achieve a complete understanding of the meaning of a given message. When the pupil 
tries to understand the text received, the reconstruction of its meaning is evidently based on the anticipation developed when formulating the question or developing the dialogue. In this way students can ignore the numerous syntactical or grammatical errors present in the messages received and can reconstruct meaning on the basis of what they were expecting in the message or of what was hinted at in the communication process.

\section{Development of planning in writing}

We have observed that communication with a real-life person gives pupils an opportunity to develop the cognitive processes needed to identify and define their communication aims, and to consequently plan their communication actions. The following example well explains our claim [1].

In the first experiment, by means of LIS (Italian Sign Language) [4], a problem was posed to four deaf children to solve. On our invitation, after discussing and comparing their solution strategies (through graphs and mimic), they wrote out the text of the problem in order to propose it to other children. All texts produced not only contained parts describing the problem situation, but also parts which described their solution strategy. In other words, the children seemed unable to perform a correct plan in relation with the given task. The actual communication with children of other schools helped them recognize their errors and correct them.

For example, one of the children, during communication, advised his interlocutor of the objective of the communication ('a problem'). He then immediately realized that the text he had previously prepared, was unsuitable for the purpose and he then wrote down a more appropriate one. The communication context helped the child escape from a simulated situation and actually think about the way in which his interlocutor would use the text he was going to send him. This helped the pupil to define his aim and to consequently plan his action.

\section{Development of lexical and syntactic capabilities in reading and writing}

The communication situations we have designed favour the acquisition of linguistic structures which are new to the children and strengthen their lexical capabilities. These effects can very clearly be seen in the dialogue enacted between a deaf adult and a deaf child. The deaf adult was able to establish an intense and emotional contact with the child in which linguistic structures played a role, which he wished to bring over on the pupil. For instance, in the second experiment, the deaf child for some time was exposed to the use of the reflexive structure which she herself was unable to use. This structure was used regularly by the adult in the messages sent to the pupil. The questions sent by the adult were, moreover, so structured that the pupil was induced to reuse the reflexive structure when she answered. We noted that after a while 
the child used the reflexive structure 'spontaneously' and that she seemed to have mastered it in a correct way.

Similar effects were found in the other two experiments. For example, in all dialogues children in most cases used interrogative sentences. In the beginning of the experiments many children were only able to pose very elementary questions. For example, they composed questions by adding the expression 'and you?' at the end of an affirmative statement ("I have black hair. And you?"). The mastering of more advanced interrogative structures was the result of exposure to various linguistic forms in the dialogue with their interlocutors. The learning took place after they had answered these more advanced questions, in doing so having understood the role and function of the different structures used in the dialogue.

The experiments carried out were very useful also with regard to the lexical development of deaf children. For example when, in the course of a computer mediated dialogue, pupils came across an unknown term which made it impossible to grasp the meaning of a sentence, the prevailing behaviour was to ask for explanations ("what does this word mean?"). The spontaneity of this behaviour (asking for an explanation) can be ascribed to the specific communication situation as, generally, pupils do not behave so when they come across unknown terms in everyday classroom practice. In ordinary reading activities more often than not pupils are not even aware of not having understood.

\section{ACKNOWLEDGEMENT}

The RETE system, the first and the second project have been realized through a collaboration among IMA-CNR, XVI USL of Genova and IRRSAE Liguria. The third project has been realized through a collaboration between IMA-CNR and AREA of Torino.

\section{REFERENCES}

1. Chiappini, G., Conte M. P., Cosma. S.and Lowemberger, F. (1991) Comunicazione per mezzo di calcolatori collegati tramite modem e sviluppo cognitivo dei bambini sordi. Proceedings of $2^{\circ}$ Convegno Nazionale Informatica, Didattica e Disabilità, Pisa (Italy), pp. 122-135.

2. Ferreiro, E., Teberosky, A. (1985) La costruzione della lingua scritta nel bambino. Giunti - Barbera, Firenze (Italy). 
3. Parisi, D. (ed) (1979) Per una educazione linguistica razionale. Il Mulino, Bologna (Italy).

4. Caselli, M.C., Maragna, S., Rampelli, L.P.and Volterra, V. Linguaggio e sordità. La Nuova Italia Editrice, Firenze (Italy).

5. Ahern, T.C., Peck, K.and Laycock, M. (1992) The effects of teacher discourse in computer-mediated discussion. Journal of Educational Computing Research 8 (3) pp. 291-309. 